\title{
Detection of HCV RNA by the Asymmetric Gap Ligase Chain Reaction
}

\author{
R.L. Marshall, T.G. Laffler, M.B. Cerney, J.C. Sustachek, J.D. Kratochvil, and R.L. Morgan
}

Abbott Laboratories, Molecular Diagnostics, Abott Park, Illinois 60064

\begin{abstract}
The ligase chain reaction (LCR) and the gap ligase chain reaction (gLCR) are exponential amplification techniques for the detection of DNA sequences in a sample. Both techniques depend on the enzyme, DNA ligase, to join adjacent probes annealed to a DNA molecule. However, DNA ligase joins DNA inefficiently on an RNA target. Consequently, LCR and gLCR cannot amplify RNA efficiently. RNA detection methods using LCR or gLCR require a CDNA synthesis step. The carryover of four dNTPs from the CDNA reaction inhibits $\mathrm{gLCR}$. Although LCR can use CDNA reaction products directly, background generated by blunt-end ligation does not allow the high sensitivity typically needed for HIV or HCV detection. The asymmetric gap ligase chain reaction (ACLCR) is a modification of gLCR that allows for the detection of RNA by using $\leqslant 3$ of the 4 nucleotides in the CDNA step and the gLCR step. Fewer than 50 copies of synthetic RNA transcript can be reproducibly detected. HCV, an RNA virus with no DNA intermediate, was chosen as the initial RNA model system. HCV antibody-positive and normal samples were analyzed, and the results were found to correlate with the results obtained using nested RNA-PCR. AGLCR provides a new nucleic acid amplification technique that can aid in the diagnosis of disease when the detection of RNA is critical.
\end{abstract}

A number of techniques are available for the detection of RNA. For high sensitivity, exponential amplification techniques such as PCR and ligase chain reaction (LCR) are necessary. LCR utilizes four probes: two adjacent probes specific for one strand of the DNA and two adjacent probes complementary to the first two probes. Hybridization of adjacent probes to a DNA target forms a ligatable substrate for thermostable DNA ligase. The ligated probes subsequently serve as a DNA target for aligning the opposite sense adjacent probes. Repeated cycles of denaturation, annealing, and ligation result in exponential amplification. ${ }^{(1-13)}$ The sensitivity of blunt LCR may be limited, possibly by target-independent ligation. ${ }^{(2)}$ This may preclude the use of this method when high sensitivity is needed. Gap LCR (gLCR) is a version of LCR where the probes are not adjacent but are separated by 2 to 3 bases on both the sense and antisense strand. ${ }^{(14,15)}$ This prevents target-independent ligation. A thermostable DNA polymerase, supplied with $<4$ dNTPs, adds the missing bases to the 3 ' internal end of one of the two probes using the DNA target as template. Once the gap between the two probes is filled, the probes are once again adjacent and can be ligated. The same process occurs on the opposite strand. Both LCR and gLCR work well on DNA but not on RNA targets. DNA ligase ligates adjacent DNA oligonucleotides that are hybridized to an RNA target very inefficiently (data not shown). RNA is detected indirectly by synthesis of a cDNA prior to LCR or gLCR. The presence of all four dNTPs from the cDNA reaction interferes with gLCR by allowing uncontrolled extension of the LCR probes by the polymerase. Therefore, the dNTPs must be removed from the cDNA product quan- titatively before the cDNA can be amplified by gLCR.

Asymmetric gLCR (AGLCR) is a version of gLCR that allows the direct use of CDNA reaction products. Sequences have been identified and probes designed to give asymmetric gaps between the sense and antisense gLCR probes. The sequences of the gaps contain $\leqslant 3$ of the 4 possible nucleotides. This controls extension of the probes and allows the product of the cDNA reaction to be used directly in the gLCR step. Such sequences are abundant in hepatitis $\mathrm{C}$ virus $(\mathrm{HCV})$, human immunodeficiency virus (HIV), and all of the potential targets investigated to date. The gaps are described as asymmetric because there is a large gap between the probes that are complementary to the RNA target and a small gap between the probes that are the same sense as the RNA target. A fourprobe AGLCR design is illustrated in Figure 1 . This design typically allows the 9to 15-base cDNA extension of the AGLCR probe (probe 4 ) using $\leqslant 3$ of the 4 dNTPS. The extended portion is complementary to a 9- to 15-base sequence at the 3 ' end of the opposite sense AGLCR probe (probe 1). When all AGLCR probes are allowed to hybridize, the extended cDNA AGLCR probe (probe 4) enables the formation of a four-probe DNA complex ligatable by DNA ligase. This ligated DNA product is then amplified by gLCR. If no RNA target-dependent cDNA extension occurs, the hybridization complex cannot form and amplification cannot take place.

\section{MATERIALS AND METHODS AGLCR}

The first step of AGLCR is a limited cDNA synthesis in which one of the four LCR 


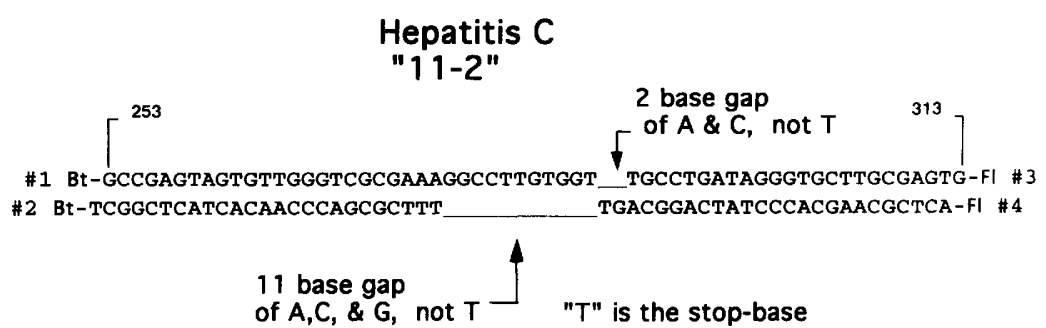

FIGURE 1 Design of AGLCR probes. The AGLCR probes map to the highly conserved 5 -untranslated region of HCV (bases 252-313, HP CHUMR, GenBank v. 71, accession no. M58335). A potential AGLCR gap sequence has the properties of a short 2- to 4-base run of less than all 4 nucleotides on the sense strand and a much longer run of 9-15 bases of the same nucleotides proceeding in the opposite direction on the antisense strand. The runs, referred to as gaps, are underlined. The HCV design is referred to as an 11-2 because there is a 2-base gap on the sense strand and an 11-base gap on the antisense strand. During AGLCR only the nucleotides that comprise the gap are supplied. Consequently, the omitted nucleotide $T$ serves as a stop base. The absence of the stop base terminates extension during both the cDNA and LCR steps of AGLCR (see Fig. 2). Probe length is chosen to give probe 1 and 2 and 3 and 4 hybrid pairs melting temperatures of $\sim 75^{\circ} \mathrm{C}$ in the LCR buffer. The probes themselves do not include the sequences in the lined gaps.

RNAUAGUGUUGGGUCGCGAAAGGCCUUGUGGUACUGCCUGAUAGGGUGCUUGCGAGUGCCCCGGGAGGUCUCGRNA TGACGGACTATCCCACGAACGCTCA--- Probe \#4

\section{STEP 1}

Reverse transcription with dCTP, dGTP, dATP only!

RNAUAGUGUUGGGUCGCGAAAGGCCUUGUGGUACUGCCUGAUAGGGUGCUUGCGAGUGCCCCGGGAGGUCUCGRNA Extension stops CCGGAACACCATGACGGACTATCCCACGAACGCTCA-extended Probe \#4 when dTTP is required.

\section{STEP 2 Ligase \& Polymerase.}

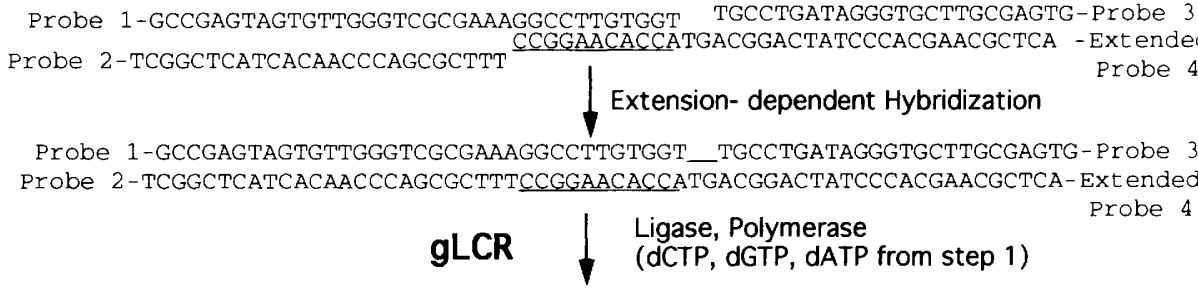

Probe 1-GCCGAGTAGTGTTGGGTCGCGAAAGGCCTTGTGGTACTGCCTGATAGGGTGCTTGCGAGTG-Probe 3 Probe 2-TCGGCTCATCACAACCCACCGCTTTCCGGAACACCATGACGGACTATCCCACGAACGCTCA-Extended

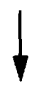

Probe 4

LCR-Amplifiable DNA from original RNA

FIGURE 2 The first step of AGLCR is a limited cDNA extension of probe 4 . The probe hybridizes to the target RNA, and reverse transcriptase extends the probe with the nucleotides $A, G$, and $C$. The extension is terminated precisely by the absence of the nucleotide $T$ in the reaction. The nucleotide $\mathrm{A}$ in the template RNA serves as a terminator base for cDNA/AGLCR. In the second step of AGLCR, the remaining three AGLCR probes, thermostable ligase, and thermostable DNA polymerase are added. The second step of AGLCR takes advantage of the extension to the cDNA probe 4 from step 1. Probe 4 , with its extension underlined, can now hybridize to probe 1 via its 11-base overlap. If no extension occurred during the cDNA step this would not be possible. Probe 2 hybridizes to probe 1, and probe 3 hybridizes to probe 4 to form a four-probe-DNA hybridization complex. In this complex the extended probe 4 can be ligated directly to probe 2 by DNA ligase. On the sense strand, probe 1 first must be extended 2 nucleotides by DNA polymerase. The absence of $T$ allows the precise termination of the extension. After extension by polymerase, probe 1 becomes directly ligatable to probe 3 . When the ligations are completed, a DNA replica of the RNA has been formed. The ligated DNA hybridization complex can be denatured, and each DNA strand serve as a template for further gap LCR amplification. This amplification normally requires $40-50$ cycles of thermal denaturation $\left(97^{\circ} \mathrm{C}\right.$ for $\left.1 \mathrm{sec}\right)$ followed by extension and ligation $\left(62^{\circ} \mathrm{C}\right.$ for $\left.50 \mathrm{sec}\right)$. This DNA amplification is identical to that described for routine gLCR. probes (probe 4 ) is extended on an RNA target in the presence of $\leqslant 3$ of the 4 dNTPs by reverse transcription (Fig. 2). This extension terminates precisely when the RNA sequence specifies the addition of the base that is not supplied. The extended cDNA probe is denatured from the RNA, and the three additional AGLCR probes, a thermostable DNA ligase, and a thermostable DNA polymerase are then added. The second step of AGLCR uses the newly synthesized 3' extension of the cDNA probe 4 as a "sticky end" complementary to the opposite sense 3 ' end of probe 1 . A ligatable four-probe hybridization complex is formed with the remaining AGLCR probes. DNA ligase can ligate the extended CDNA probe 4 to its immediately adjacent $3^{\prime}$ AGLCR probe 2 when the two probes are both hybridized to the opposite sense AGLCR probe 1 . The opposite sense AGLCR probes 1 and 3 both can hybridize to the extended cDNA probe, but a gap of a few bases lies between them. The thermostable DNA polymerase fills the gap using the extension of cDNA probe 4 as a template. Once the gap is filled, the oligonucleotide probes are immediately adjacent and DNA ligase joins them. These two ligated probe products now function as AGLCR-amplifiable DNA targets when denatured from one another. As the process of extension-ligation is repeated in each thermal cycle of denaturation and annealing, exponential amplification results. If no RNA target is present in the sample, the four-probe hybridization complex cannot form and no amplification results. RNA is required only during the initial cDNA step. The cDNA step can use either reverse transcriptase or a thermostable DNA polymerase shown to have reverse transcriptase activity in the presence of $\mathrm{Mn}^{++} \cdot(16,17)$

\section{AGLCR Using Reverse Transcriptase for the CDNA Step}

The cDNA reaction $(20 \mu \mathrm{l})$ was incubated in $650-\mu$ l Slickseal microcentrifuge tubes (ISS, Natick, MA). Reaction components were $2 \mu$ l of RNA target, 20 units of Moloney murine leukemia virus (MMLV) reverse transcriptase (BRL, Gaithersberg, MD), $10 \mu \mathrm{M}$ dNTPs (Pharmacia, Piscataway, NJ), and $1 \times 10^{12}$ molecules of the cDNA AGLCR probe in buffer consisting of $10 \mathrm{~mm}$ Tris- $\mathrm{HCl}(\mathrm{pH} 8.0), 50 \mathrm{~mm} \mathrm{KCl}$, and $5 \mathrm{mM} \mathrm{MgCl}_{2}$. The reaction was incu- 
bated at $37^{\circ} \mathrm{C}$ for $30 \mathrm{~min}$ followed by $99^{\circ} \mathrm{C}$ for $5 \mathrm{~min}$ to inactivate the reverse transcriptase and $4^{\circ} \mathrm{C}$ for $5 \mathrm{~min}$.

\section{AGLCR CDNA Amplification}

The AGLCR mixture $(180 \mu \mathrm{l})$ was added to the $20-\mu l$ cDNA reaction. The LCR mixture contained $1 \times 10^{12}$ molecules of LCR probes 1, 2, and 3, 9000 units of thermostable Thermus thermophilus DNA ligase (Abbott Laboratories, Abbott Park, II), and 0.5 units of thermostable Thermus sp. DNA polymerase (MBR, Milwaukee, WI) in a buffer consisting of Tris$\mathrm{HCl}(\mathrm{pH} \mathrm{7.7)}, 19 \mathrm{~mm} \mathrm{KCl}$, and $30 \mathrm{~mm}$ $\mathrm{MgCl}_{2}$. The LCR reaction was cycled (denaturation and annealing extension/ligation) for $40-43$ cycles of $97^{\circ} \mathrm{C}$ for $1 \mathrm{sec}$, $55^{\circ} \mathrm{C}$ for $1 \mathrm{sec}$, and $62^{\circ} \mathrm{C}$ for $50 \mathrm{sec}$ in a model 480 Thermal Cycler (PerkinElmer, Norwalk, CT).

\section{IMx Microparticle Enzyme Immunoassay Detection}

AGLCR product was detected by microparticle enzyme immunoassay (MEIA) automated by the Abbott IMx. (18) Only the complete bidentate LCR product could be captured by microparticles and detected by conjugate. The hapten fluorescein $(\mathrm{Fl})$ was used on the $5^{\prime}$ end of probe 1 and the $3^{\prime}$ end of probe 2 to enable the anti-hapten-antibody microparticle capture of AGLCR product. The hapten biotin was used on the 3 ' end of probe 3 and the 5 end of probe 4 to enable the anti-hapten-antibody alkaline phosphatase conjugate detection. The substrate methylumbelliferyl phosphate (MUP) is converted to a fluorescent product by alkaline phosphatase, indicating the presence of complete LCR product. The rate at which the fluorescent product is generated was expressed in counts per second per second $(\mathrm{c} / \mathrm{s} / \mathrm{s})$.

\section{Oligonucleotide Probe Synthesis}

Oligonucleotide probes were synthesized on an ABI 394 DNA synthesizer and purified by gel electrophoresis. Quantitation was by $\mathrm{OD}_{260}$.

\section{HCV Probes and Primers}

HCV AGLCR and PCR primers were chosen from the highly conserved 5'-untranslated region of the $\mathrm{HCV}$ virus. The set of four AGLCR probes mapped to nucleotide positions 253-313 (Table 1 and Fig. 1). The set of first-round PCR primers (C2 and 19-1) amplified a 250-bp product in the 5 '-untranslated region of $\mathrm{HCV}$. The internal primer set ( $\mathrm{C} 1$ and 4-1) resulted in the amplification of a 157-bp nested PCR product (Table 1).

\section{RNA Templates}

Plasmid pHCV 136-7, containing the 5 -untranslated region of $\mathrm{HCV}$ was provided by Suresh Desai (Abbott Laboratories). It was confirmed by DNA sequencing to contain the 281-bp HCV nucleotide sequence 19-299 (HPCHUMR, GenBank v. 71, accession no. M58335). HindIII-linearized pHCV136-7 was used for transcription.

Positive control RNA was made by transcription using the Riboprobe II kit (Promega Corp., Madison, WI) according to the manufacturer's instructions. Reactions were extracted with 1 volume of $10 \mathrm{~mm}$ Tris- $\mathrm{HCl}(\mathrm{pH} 8)$ and $1 \mathrm{~mm}$ EDTA (TE)-saturated phenol/chloroform. The upper aqueous phase was isolated and extracted with an equal volume of chloroform/isoamyl alcohol (24:1). The upper aqueous phase was reisolated, and 0.5 volume of $7.5 \mathrm{M}$ ammonium acetate and 2.5 volumes of ethanol were added. RNA was precipitated for $30 \mathrm{~min}$ at $-20^{\circ} \mathrm{C}$ followed by a 5 -min centrifugation at $10,000 \mathrm{~g}$. The RNA pellet was washed with $70 \%$ ethanol, centrifuged, and resuspended in TE. The RNA concentration was determined spectrophotometrically by $\mathrm{OD}_{260}$. Ribosomal $16 \mathrm{~S}$ and 23S RNA (Boehringer Mannheim, Indianapolis, IN) at $2.0 \mathrm{ng} / 2 \mu \mathrm{l}$ was used as a carrier in all dilutions of RNA and as an AGLCR/PCR-negative control.

\section{Clinical Samples}

$\mathrm{HCV}$ plasma samples from both antibody-negative and -positive human donors were purchased from Antibody Systems, Inc. (Bedford, TX), Consumer Biologicals, Inc. (Miami, FL), Serologicals, Inc. (Clarkston, GA), LifeSource (Glenview, IL), and The Blood Center of Southeastern Wisconsin (Milwaukee, WI).

\section{Sample Preparation}

RNA was isolated using the RNAzol B kit (Tel/Test, Inc., Friendswood, TX) according to the manufacturer's instructions. Plasma $(100 \mu \mathrm{l})$ was added to $900 \mu \mathrm{l}$ of the RNAzol B reagent. MS2 RNA was used as carrier RNA for the precipitation steps. The prepared RNA was precipitated as above and resuspended in $20 \mu \mathrm{l}$ of diethyl pyrocarbonate (DEPC)-treated wa-

TABLE 1 Oligonucleotide Probes and Primers

\begin{tabular}{|c|c|c|c|}
\hline \multicolumn{2}{|c|}{$\mathrm{HCV}$ target } & & \multirow[b]{2}{*}{ Sequence $\left(5^{\prime} \rightarrow 3^{\prime}\right)$} \\
\hline type & position & & \\
\hline AGLCR 1 & $253-287$ & (5' UTR) & bt-GCCGAGT AGTGTTGGGTCGCGAAAGGCCTTGTGGT \\
\hline AGLCR 3 & $290-313$ & (5' UTR) & p-TGCCTGATAGGGTGCTTGCGAGTG-fl \\
\hline AGLCR 4 & c312-288 & (5' UTR) & fl-ACTCGCAAGCACCCTATCAGGCAGT \\
\hline AGLCR 2 & $c 276-252$ & ( $5^{\prime}$ UTR $)$ & p-TTTCGCGACCCAACACTACTCGGCT-bt \\
\hline PCR (19-1) & $19-45$ & (5' UTR) & C ACCATAGATCACTCCCCTGTGAGGAA \\
\hline PCR (C2) & $\mathrm{c} 268-250$ & (5' UTR) & C T TTCGCGACCCAACACTA \\
\hline PCR (4-1) & $100-121$ & (5' UTR) & A GCCTCCAGGACCCCСССТ CCC \\
\hline PCR (C-1) & c237-256 & (5' UTR) & A ACACTACTCGGCTAGCAGT \\
\hline
\end{tabular}

Nucleotide sequences were derived from GenBank v. 71, HCV accession number M58335. The haptens fluorescein (fl) and biotin (bt) were used for detection of AGLCR product by enzyme immunoassay. AGLCR probes 3' to the gap were 5' phosphorylated (p) to allow ligation to the 3' hydroxyl groups. Nucleotide sequences complementary to HCV RNA are designated by the letter $\mathrm{c}$. 
ter $\left(5^{\prime}-3^{\prime}\right.$ Inc., Boulder, CO). Purified RNA $(2 \mu \mathrm{l})$ equivalent to $10 \mu \mathrm{l}$ of original plasma, was used in AGLCR and PCR assays.

\section{RNA-PCR}

RNA was reverse transcribed and amplified using the GeneAmp RNA PCR kit (Perkin-Elmer, Norwalk, CT) as follows. Reverse transcription reactions were performed by incubating $2 \mu \mathrm{l}$ of RNA in a $20-\mu$ l reaction containing $1 \mathrm{~mm}$ of each deoxyribonucleotide (dATP, dGTP, dCTP, dTTP), 50 units of reverse transcriptase, 20 units of RNase inhibitor, $0.75 \mu \mathrm{M}$ antisense primer (C2), $10 \mathrm{~mm}$ Tris- $\mathrm{HCl}$ (pH 8.3), $50 \mathrm{~mm} \mathrm{KCl}$, and $5 \mathrm{~mm}$ $\mathrm{MgCl}_{2}$. Reactions were terminated by incubation at $99^{\circ} \mathrm{C}$ for $5 \mathrm{~min}$, followed by $5^{\circ} \mathrm{C}$ for $5 \mathrm{~min}$. PCR amplification of the cDNA was performed in a $100-\mu$ l volume containing a final concentration of 2.5 units of AmpliTaq DNA polymerase and $0.15 \mu \mathrm{M}$ sense primer (19-1) in $10 \mathrm{~mm}$ Tris- $\mathrm{HCl}(\mathrm{pH} \mathrm{8.3)} 50 \mathrm{~mm} \mathrm{KCl}$, and $2 \mathrm{~mm}$ $\mathrm{MgCl}_{2}$. Reactions were incubated at $95^{\circ} \mathrm{C}$ for $2 \mathrm{~min}$, followed by 35 cycles of denaturation at $95^{\circ} \mathrm{C}$ for $1 \mathrm{~min}$ and annealing/extension at $60^{\circ} \mathrm{C}$ for $1 \mathrm{~min}$. A final extension was performed at $60^{\circ} \mathrm{C}$ for 7 min. Thermal cycling was performed with a model 480 thermal cycler (PerkinElmer, Norwalk, CT).

Nested PCR (nPCR) was performed by the addition of $2 \mu \mathrm{l}$ ( $1 / 50$ volume) of the first-round PCR reaction to $98 \mu \mathrm{l}$ of PCR mixture containing a final concentration of $0.15 \mu \mathrm{M}$ each of antisense primer (C1) and sense primer (4-1), $200 \mu \mathrm{M}$ dATP, dGTP, dCTP, and dTTP, and 2.5 units of AmpliTaq DNA polymerase in 10 $\mathrm{mm}$ Tris- $\mathrm{HCl}$ ( $\mathrm{pH} \mathrm{8.3),} 50 \mathrm{~mm} \mathrm{KCl}$, and 2 $\mathrm{mM} \mathrm{MgCl}_{2}$. Cycling conditions were identical to first-round PCR. PCR products were electrophoresed on $3 \% \mathrm{Nu}$ Sieve/1\% SeaKem LE agarose (FMC Corp., Rockland, MA) in the presence of $90 \mathrm{~mm}$ Tris-borate ( $\mathrm{pH} \mathrm{8.0)}$ and $2 \mathrm{~mm}$ EDTA buffer (TBE), containing $500 \mathrm{ng} /$ $\mathrm{ml}$ of ethidium bromide (EtBr).

\section{RESULTS}

\section{Sensitivity of AGLCR}

Twenty molecules of $\mathrm{HCV}$-purified recombinant RNA transcript were detected by AGLCR (Fig. 3). In our hands, this was equivalent to the sensitivity of nested RNA-PCR using gel electrophoresis and
EtBr as the product detection method (data not shown). No amplification was detected using RNA as a target when reverse transcriptase was omitted from the cDNA step. This verified that the reaction detected RNA and not residual DNA.

\section{Sample Data}

The ability of HCV AGLCR to differentiate negative from positive samples was tested with 50 normal HCV antibodynegative donor samples and $18 \mathrm{HCV}$ positive donor samples. Two microliters of each purified RNA, equivalent to $10 \mu \mathrm{l}$ of plasma, was tested. HCV viremia was detected in all 18 of the HCV antibodypositive samples, and none of the normal donor samples were positive for HCV RNA (Fig. 4). The mean of the antibody-negative samples was $32.18 \mathrm{c} / \mathrm{s} / \mathrm{s}$ with a standard deviation of $25.32 \mathrm{c} / \mathrm{s} / \mathrm{s}$. Ten standard deviations above the mean of the negative sample population $(285.38 \mathrm{c} / \mathrm{s} / \mathrm{s})$ was chosen as the cutoff to differentiate positive samples from negative samples. This number of standard deviations would be acceptable for a screening assay. The AGLCR results correlated $100 \%$ with $\mathrm{HCV}$ antibody status and with PCR in this limited study.

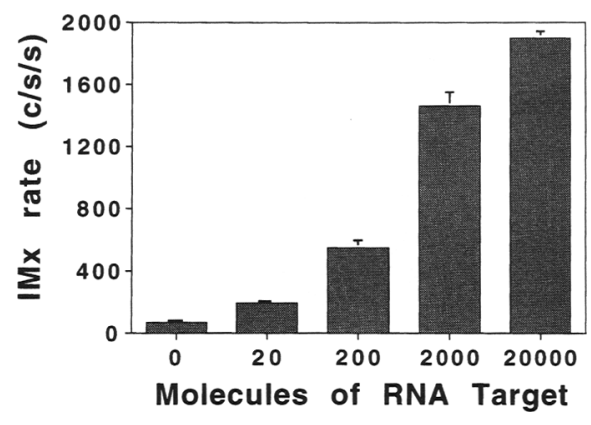

FIGURE 3 Sensitivity of AGLCR. The sensitivity of AGLCR was determined using purified synthetic RNA transcripts made from HCV DNA cloned into the transcription vector pKS + Bluescript (pHCV 136-7). The RNA was quantitated spectrophotometrically by $A_{260}$. Dilutions of the HCV RNA were made into $2 \mathrm{ng} / \mu \mathrm{l}$ of carrier RNA (16S/23S rRNA). The carrier RNA also served as the negative control. RNA $(2 \mu \mathrm{l})$ was tested in duplicate by AGLCR. MMLV reverse transcriptase was used in the cDNA step and followed by 40 cycles of gLCR. Twenty molecules of purified HCV transcript RNA were detected over the rRNA used as a negative control (shown as the 0 target data point). Error bars (1 S.D.) are included for all data points. The 20 -molecule RNA control mean is separated from the rRNA negative control mean by 5 s.Ds. The amount of amplicon produced was quantitated by a MEIA performed on the Abbott IMx analyzer.

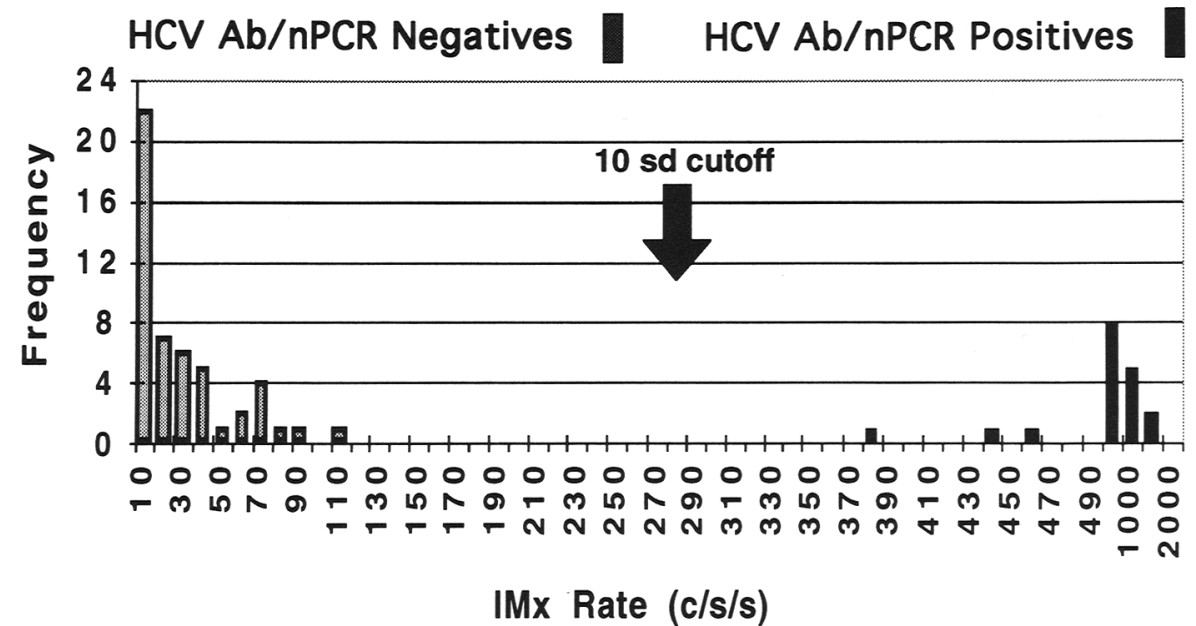

FIGURE 4 Performance of AGLCR on HCV clinical samples. RNA was extracted from $100 \mu \mathrm{l}$ of plasma using a commercially available solvent-based extraction product [RNAzol B (Tel-Test, Inc., Friendswood, TX)]. RNA pellets were dissolved in $20 \mu \mathrm{l}$ of DEPC-treated water containing $400 \mathrm{ng}$ of MS2 RNA as carrier. AGLCR determinations were performed on $2 \mu 1$ aliquots equivalent to $10 \mu \mathrm{l}$ of original plasma. The test population included 50 normal HCV antibody/nPCR-negative and $18 \mathrm{HCV}$ antibody/nPCR-positive donors. The cutoff value of $285.38 \mathrm{c} / \mathrm{s} / \mathrm{s}$ is $10 \mathrm{~s} . \mathrm{D} . \mathrm{s}$ above the mean of the negative samples. Note that the right portion of the graph $(>500 \mathrm{c} / \mathrm{s} / \mathrm{s})$ was compressed for illustration. The amount of amplicon produced was quantitated by MEIA performed on the Abbott IMx analyzer. The sensitivity of AGLCR was 20 molecules, based on purified synthetic RNA transcript. The positive sample cutoff was 10 S.D.s above the mean of the HCV-negative samples. 


\section{DISCUSSION}

AGLCR is a variant of gLCR, which allows the sensitive detection of RNA as well as DNA. Its ability to detect RNA was demonstrated with HCV-containing samples where no DNA exists. We have shown that AGLCR can detect as few as 20 copies of purified recombinant RNA templates and is comparable to RNAPCR, using EtBr-stained gels as the PCR product detection method. AGLCR detects DNA $\sim 10$-fold better than RNA (data not shown). This indicates an apparent inefficiency in the cDNA step. Therefore, appropriate techniques or controls must be included to ensure that AGLCR or RNA-PCR signal is generated from RNA and not DNA.

The AGLCR technique has been applied to the detection of HCV RNA in clinical samples. HCV viremia was detected easily in $\mathrm{HCV}$ antibody-positive donors but not in antibody-negative normal donors. AGLCR has the potential, as does RNA-PCR, to detect $\mathrm{HCV}$ early in the course of infection before seroconversion or antigenemia has occurred. Seroconversion takes an average of 22 weeks to occur after infection, but viral RNA can be detected as early as $10-$ 14 days postexposure. ${ }^{(17,19)}$ The utility of AGLCR for the detection of HCV viremia prior to seroconversion and its value for the study of the natural history of $\mathrm{HCV}$ infection and therapeutic monitoring are under investigation. The use of $\mathrm{HCV}$ RNA as a marker for persistent $\mathrm{HCV}$ viremia has been demonstrated. ${ }^{(20)}$ It may be used also to differentiate patients with ongoing active $\mathrm{HCV}$ infection from those with an acute resolving disease. ${ }^{(20)}$ AGLCR is a new nucleic acid amplification technique for RNA detection. AGLCR should prove to be a highly sensitive and valuable research and diagnostic tool for the detection of RNA pathogens. Potentially, AGLCR may be useful in the analysis of mRNAs in genetic diseases, mRNA expression levels, and the detection of structural RNAs of pathogens.

\section{ACKNOWLEDGMENTS}

We thank Mike Klass and George Dawson for helpful discussions and Eve Anderson for review of the manuscript.

\section{REFERENCES}

1. Backman, K. 1992. Ligase chain reaction:
Diagnostic technology for the 1990s and beyond. Clin. Chem. 38: 457-458.

2. Barany, F. 1991. Genetic disease detection and DNA amplification using cloned thermostable ligase. Proc. Natl. Acad. Sci. 88: 189-193.

3. Barany, F. 1991. Ligase chain reaction in a PCR World. PCR Methods Applic. 5: 5-16.

4. Birkenmeyer, L. and A. Armstrong. 1992. Preliminary evaluation of the ligase chain reaction for specific detection of Neisseria gonorrhoeae. J. Clin. Microbiol. 30: 30893094.

5. Bond, S., J. Carrino, H. Hampl, K. Hanley, L. Rinehardt, and T. Laffler. 1990. New methods of detection of HPV. In Papillomaviruses in epidermoid precancers (ed. J. Monsenego), pp. 425-434. Raven Press, New York.

6. Dille, B.J., C.C. Butzen, and L. Birkenmeyer. 1993. Ampification of Chlamydia trachomatis DNA by ligase chain reaction. J. Clin. Microbiol. 31: 729-731.

7. Hampl, H., R.L. Marshall, T. Perko, and N. Solomon. 1991. Alternative methods for DNA probing in diagnosis: Ligase chain reaction (LCR). In PCR topics (ed. A. Rolfs, H.C. Schumacher, and P. Marx), pp. 1522. Springer-Verlag, Berlin, Germany.

8. Iovannisci, D.M. and E.M. Winn-Deen. 1993. Ligation amplification and fluorescence detection of Mycobacterium tuberculosis DNA. Mol. Cell. Probes 7: 35-43.

9. Laffler, T.J., J.J. Carrino, and R.L. Marshall. 1993. The ligase chain reaction in DNA-based diagnostics. Ann. Biol. Clin. 50: $821-826$.

10. Landegren, U., R. Kaiser, J. Sanders, and L. Hood. 1988. A ligase-mediated gene detection technique. Science 241: 10771080.

11. Winn-Deen, E.S. and D.M. Iovannisci. 1991. Sensitive fluorescence method for detecting DNA ligation amplification products. Clin. Chem. 7: 179-186

12. Winn-Deen, E.S., C.A. Batt, and M. Wiedmann. 1993. Non-radioactive detection of Mycobacterium tuberculosis LCR products in a microtitre plate format. Mol. Cell. Probes 7: 179-186.

13. Wu, D.W. and R. B. Wallace. 1989. The ligation amplification teaction (LAR) Amplification of specific DNA sequences using sequential rounds of template-dependent ligation. Genomics 4: 560-569.

14. Birkenmeyer, L.G. and I.K. Mushahwar. 1991. DNA probe amplification methods. J. Virol. Methods 35: 117-126.

15. M.J. Wolcott. 1992. Advances in nucleic acid-based detection methods. Clin. Microbiol. Rev. 5: 370-386.

16. Meyers, T.W. and D.H. Gelfand. 1991. Reverse transcription and DNA amplification by a Thermus thermophilus DNA polymerase. Biochemistry 30: 7661-7666.

17. Young, K.K.Y., R.M. Resnick, and T.W. Meyers. 1993. Detection of hepatitis C vi- rus by a combined reverse transcriptionpolymerase chain reaction assay. J. Clin. Microbiol. 31: 882-886.

18. Fiore, M., J. Mitchell, T. Doan, R. Nelson, G. Winter, C. Grandone, K. Zeng, R. Haraden, J. Smith, K. Harris, J. Leszczynski, D. Berry, S. Safford, G. Barnes, A. Scholnick, and K. Ludington. 1988. The Abbott IMx automated bench top immunochemistry analyzer system. Clin. Chem. 34: 1726-1732.

19. Alter, H.J., R.H. Purcell, J.W. Shih, J.C. Melpolder, M. Houghton, Q. Choo, and G. Kuo. 1989. Detection of antibody to hepatitis $\mathrm{C}$ virus in prospectively followed transfusion recipients with acute and chronic non-A, non-B hepatitis. New Engl. J. Med. 321: 1494-1500.

20. Schlauder, G.G., G.J. Leverenz, L. Mattsson, O. Weiland, and I.K. Mushahwar. 1992. Detection of hepatitis C viral RNA by the polymerase chain reaction in serum of patients with post-transfusion non-A, non-B hepatitis. J. Virol. Methods 37: 189-200.

Received March 21, 1994; accepted in revised form July 6, 1994. 


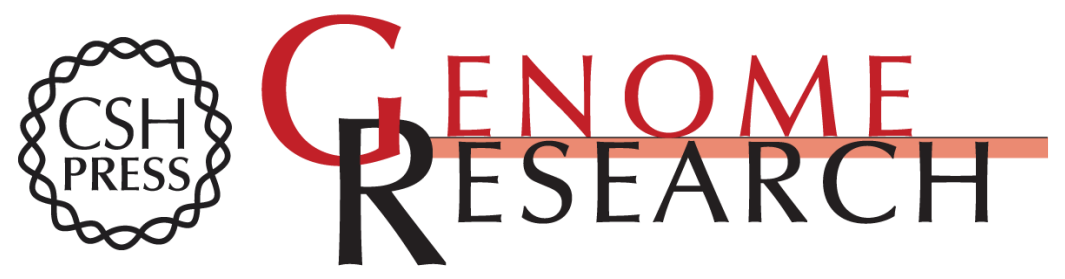

\section{Detection of HCV RNA by the asymmetric gap ligase chain reaction.}

R L Marshall, T G Laffler, M B Cerney, et al.

Genome Res. 1994 4: 80-84

References This article cites 18 articles, 8 of which can be accessed free at:

http://genome.cshlp.org/content/4/2/80.full.html\#ref-list-1

\section{License}

Email Alerting Receive free email alerts when new articles cite this article - sign up in the box at the Service top right corner of the article or click here.

\section{Affordable, Accurate Sequencing.}

To subscribe to Genome Research go to: https://genome.cshlp.org/subscriptions 